\title{
Extracellular Self-Assembly of Functional and Tunable Protein Conjugates from Bacillus subtilis
}

\author{
Charlie Gilbert, ${ }^{\dagger, \$}$ Mark Howarth, ${ }^{\S}$ Colin R. Harwood," and Tom Ellis, ${ }^{*}, \ddagger \bullet$ \\ ${ }^{\dagger}$ Centre for Synthetic Biology and Innovation, Imperial College London, London SW7 2AZ, U.K. \\ ${ }^{\star}$ Department of Bioengineering, Imperial College London, London SW7 2AZ, U.K. \\ ${ }^{\S}$ Department of Biochemistry, University of Oxford, South Parks Road, Oxford OX1 3QU, U.K. \\ "Centre for Bacterial Cell Biology, Baddiley-Clark Building, Newcastle University, Richardson Road, Newcastle upon Tyne NE2 4AX, \\ U.K.
}

\section{Supporting Information}

ABSTRACT: The ability to stably and specifically conjugate recombinant proteins to one another is a powerful approach for engineering multifunctional enzymes, protein therapeutics, and novel biological materials. While many of these applications have been illustrated through in vitro and in vivo intracellular protein conjugation methods, extracellular selfassembly of protein conjugates offers unique advantages: simplifying purification, reducing toxicity and burden, and enabling tunability. Exploiting the recently described SpyTagSpyCatcher system, we describe here how enzymes and structural proteins can be genetically encoded to covalently conjugate in culture media following programmable secretion from Bacillus subtilis. Using this approach, we demonstrate how self-conjugation of a secreted industrial enzyme, XynA, dramatically increases its resilience to boiling, and we show that cellular consortia can be engineered to self-assemble functional proteinprotein conjugates with tunable composition. This novel genetically encoded modular system provides a flexible strategy for protein conjugation harnessing the substantial advantages of extracellular self-assembly.

KEYWORDS: extracellular self-assembly, SpyTag-SpyCatcher, microbial consortia, thermotolerance, protein conjugation, tunability
$\mathrm{P}$ roteins are modular biological components whose functions can be combined, augmented and repurposed by bringing them together in new ways. Not only is this a key driver in the evolution of novel cellular processes, ${ }^{1}$ but it is also a powerful approach for the creation of a variety of biotechnological products. By linking proteins together, novel biomaterials can be assembled ${ }^{2,3}$ and functionalized ${ }^{4-6}$ and colocalizing enzymes from a single metabolic pathway can be used to enhance metabolic fluxes in biosynthesis. ${ }^{7,8}$ Vaccine efficacy can be improved by conjugating antigens to specific presentation proteins, $^{9-11}$ and therapeutic proteins can be stabilized or targeted to specific tissues or cells by fusing them to appropriate protein partners. ${ }^{12,13}$ Using tools and approaches from synthetic biology, we sought to replace the costly and technically demanding methods previously used to conjugate proteins in vitro with a modular, genetically programmable in vivo approach. The ability to program spontaneous selfassembly of protein-protein complexes from microorganisms in this way could accelerate the development of novel biotechnological products and simultaneously facilitate their on-site production without the need for user intervention.

Genetic fusion is a simple and direct method for conjugating proteins together, but is limited in the size, topology and repetitiveness of conjugates that can be formed. ${ }^{14}$ Conversely, chemical conjugation methods enable multivalent and extensible protein-protein conjugation, but typically require prior purification and treatment of proteins and so cannot be implemented in vivo. ${ }^{2,15-17}$ By contrast, biological conjugation methods such as the SpyTag-SpyCatcher system, ${ }^{18}$ enable both genetically programmed in vivo self-assembly and the formation of a variety of topologies. ${ }^{19-21}$

The SpyTag-SpyCatcher system ${ }^{18}$ directs specific, covalent conjugation of proteins through two short polypeptide tags: the SpyTag and SpyCatcher. The larger partner, the SpyCatcher, adopts an immunoglobulin-like fold that specifically binds the SpyTag and autocatalyses the formation of an intermolecular isopeptide bond between two amino acid side chains. Notably, in the few years since its initial description, ${ }^{18}$ the SpyTagSpyCatcher system has been applied to the production of programmable and customizable materials, ${ }^{5,22-25}$ synthetic vaccines, ${ }^{9}$ thermotolerant enzymes, ${ }^{26-28}$ stably packaged enzymes $^{29,30}$ and more. ${ }^{8,31-37}$

However, thus far, the SpyTag-SpyCatcher system has only ever been deployed within the cell or in vitro, following purification of individual components. Yet for a variety of

Received: October 12, 2016

Published: February 23, 2017 

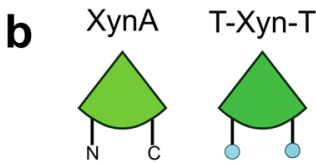

24 kDa

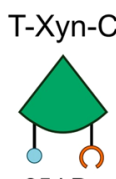

$35 \mathrm{kDa}$

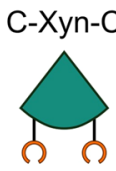

$46 \mathrm{kDa}$
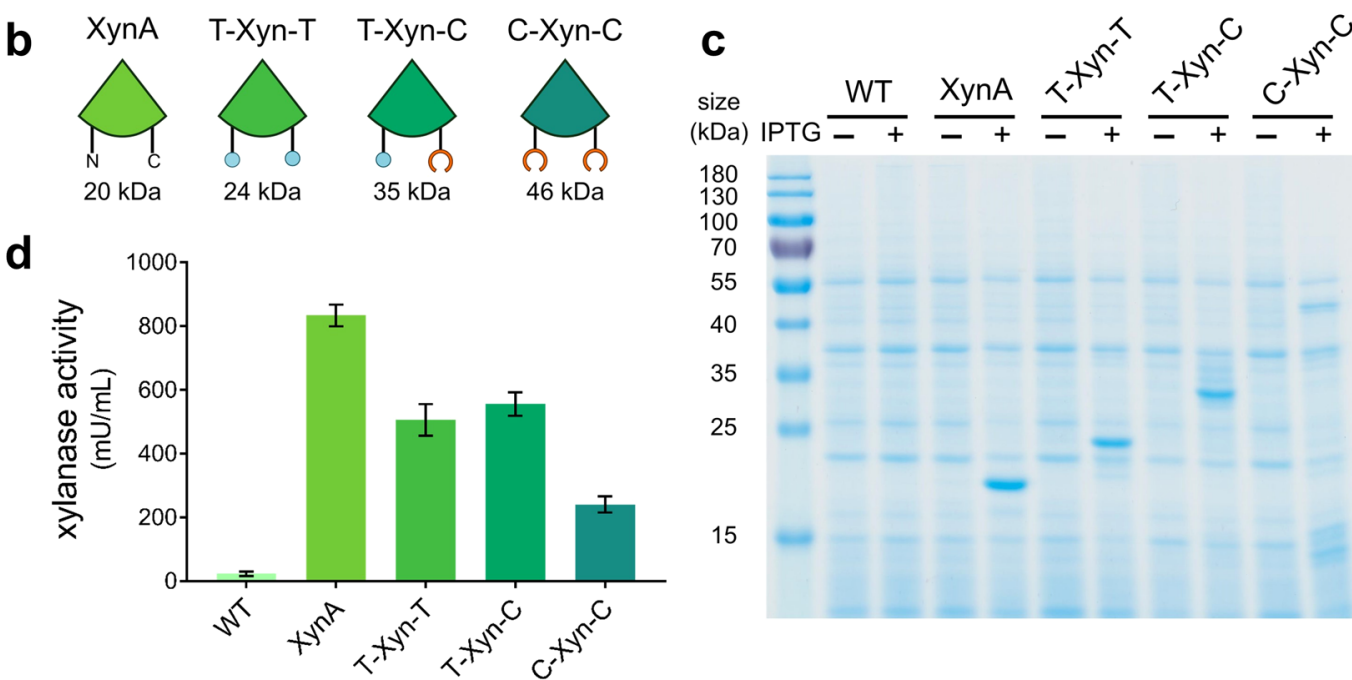

130
100

70
55

40

35

25

15

Figure 1. Design, secretion and activity of SpyTag-SpyCatcher XynA fusion proteins. (a) Protein-encoding DNA modules specifying secretion, conjugation and function were fused into single ORFs separated by 2-amino acid glycine-serine linkers. (b) Four recombinant proteins based on XynA were designed: the full-length xylanase XynA, SpyTag-XynA-SpyTag (T-Xyn-T), SpyTag-XynA-SpyCatcher (T-Xyn-C) and SpyCatcherXynA-SpyCatcher (C-Xyn-C). All possess the native XynA signal peptide at their N-termini as well as a C-terminal His ${ }_{6}$ tag. (c) Culture supernatants from uninduced $(-)$ and IPTG-induced $(+)$ cultures were 10× concentrated by TCA precipitation prior to SDS-PAGE analysis with Coomassie staining. All four proteins were well-expressed and secreted. Untransformed B. subtilis WB800N (WT) was included as a negative control. (d) Culture supernatants were analyzed for xylanase activity using a fluorogenic substrate. All samples exhibited xylanase activity, indicating secretion of active fusion proteins. Product formation rates were calculated over $10 \mathrm{~min}$ from triplicate samples (data represent the mean \pm 1 SD).

applications, it would be advantageous for proteins to be secreted prior to spontaneous conjugation. First, extracellular production greatly simplifies downstream processing and purification of products, ${ }^{38}$ improving industrial scale costeffectiveness. In addition, secreting the monomeric components of protein polymers avoids the cytotoxicity and misfolding commonly associated with their intracellular expression, facilitating applications such as protein material production. ${ }^{39}$ Lastly, by engineering microbes to secrete proteins that form complexes outside the cell, it becomes possible to compartmentalize the production of individual proteins within separate strains in a coculture. Engineering so-called "cellular consortia" to perform co-operative biological tasks in this way has attracted increasing interest in recent years due to the substantial potential advantages it offers. ${ }^{40,41}$ For instance, engineered cellular consortia allow the division of labor between cocultured strains, meaning less burden is placed on each individual cell. In addition, by separately engineering individual strains within cocultures, mixing of consortia has been used to help optimize biological processes and to enable tunable and autonomous patterning of biomaterials. ${ }^{5,41-44}$

To provide a modular platform for programmable, spontaneous growth of protein-protein conjugates, we sought to engineer simultaneous protein secretion and SpyTagSpyCatcher-mediated protein conjugation using Bacillus subtilis, a Gram-positive bacterium used extensively in industrial biotechnology ${ }^{45}$ with a considerable capacity for protein secretion (up to $20 \mathrm{~g}$ per liter ${ }^{46}$ ). We designed and built recombinant fusion proteins consisting of separate protein modules specifying function, secretion and conjugation and demonstrate here that these modules are active and direct secretion and extracellular conjugation without perturbing enzymatic activity. We illustrate the utility of our approach here in two scenarios: engineering secreted, thermotolerant enzymes for industrial biotechnology and tuning the assembly of functional, secreted protein conjugates by varying cellular consortia composition.

\section{RESULTS AND DISCUSSION}

Expression, Secretion, and Conjugation of SpyTagSpyCatcher Fusion Proteins. To first determine the feasibility of our approach-combining SpyTag-SpyCatcher conjugation and B. subtilis protein secretion-we fused together protein-encoding DNA modules specifying secretion, conjugation and function into single open reading frames (ORFs) within gene expression cassettes. Four protein modules, each connected by two amino acid glycine-serine linkers, were defined: an N-terminal secretion signal peptide, an upstream SpyPart-either SpyTag (T) or SpyCatcher (C)-then a userdefined protein of interest and a C-terminal $\mathrm{His}_{6}$-tagged SpyPart (Figure 1A).

Using this design, we first generated a series of fusion proteins based on the native, secreted $B$. subtilis endoxylanase, XynA (Figure 1B and Supplementary Figure S1), a hemicellulose-degrading enzyme with uses in industry. The native $\mathrm{XynA}$ signal peptide was preserved at the $\mathrm{N}$-terminus and SpyParts were fused either side of the $\mathrm{XynA}$ enzyme core to create three proteins: T-Xyn-T, T-Xyn-C and C-Xyn-C (Figure 1B). As a control, a construct expressing the full-length XynA with a C-terminal $\mathrm{His}_{6}$-tag was also created. All constructs were cloned downstream of the strong IPTG-inducible $P_{\text {grac }}$ promoter in pHT01, a B. subtilis-E. coli shuttle vector. Each of these fusion proteins was successfully expressed and secreted from B. subtilis (Figure 1C and Supplementary Figure S2) and retained xylanase activity (Figure 1D). 
a
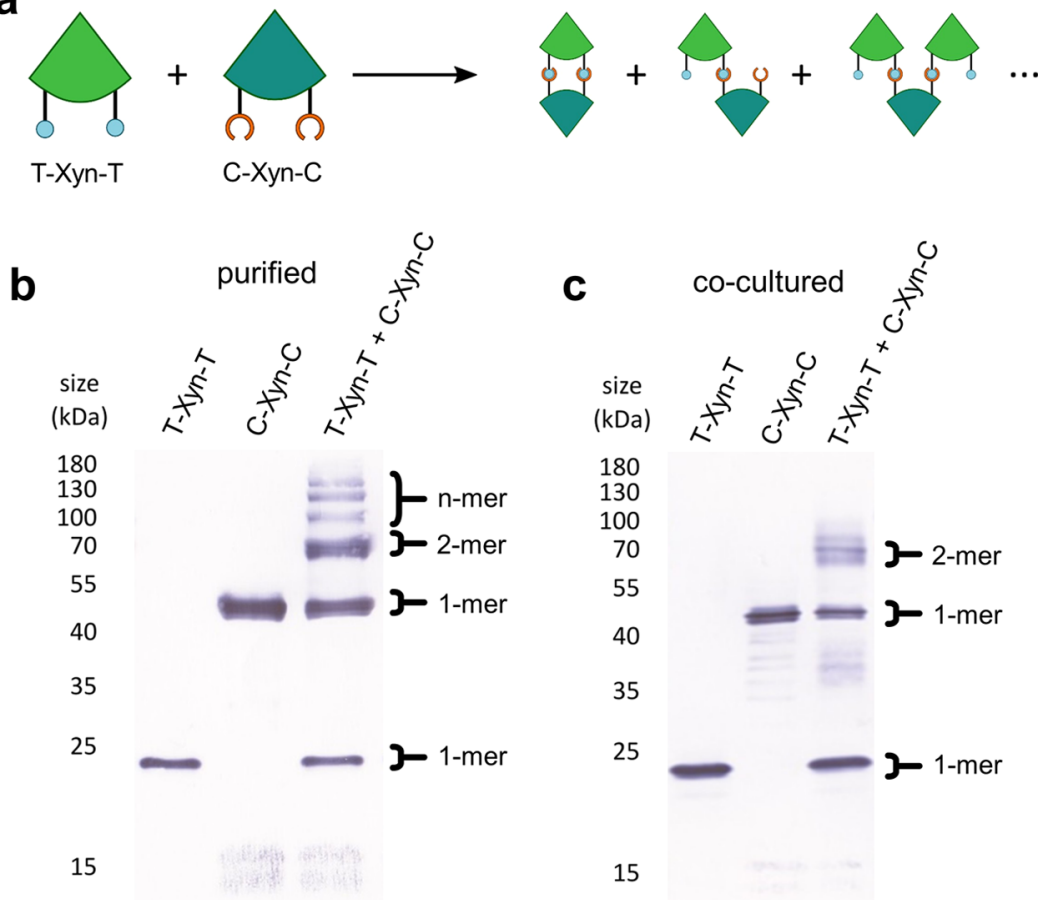

Figure 2. SpyTag-SpyCatcher-mediated protein conjugation from cocultures. (a) Schematic showing the possible reaction products between T-Xyn$\mathrm{T}$ and C-Xyn-C. (b) His $6_{6}$-tagged T-Xyn-T and C-Xyn-C fusion proteins were purified from culture supernatants by IMAC (immobilized metal ion affinity chromatography) and analyzed by Western blotting (with an anti-His ${ }_{6}$ antibody) in isolation or after mixing. (c) Supernatant samples from monocultures expressing T-Xyn-T or C-Xyn-C and a coculture of T-Xyn-T and C-Xyn-C were analyzed by Western blotting with an anti-His 6 antibody. A dimeric species was clearly discernible under coculture conditions, along with monomers of T-Xyn-T and C-Xyn-C.

To determine whether fusion of SpyParts to XynA affected its secretion, we analyzed cellular and secreted protein samples by Western blot (Supplementary Figure S3). For the T-Xyn-T and C-Xyn-C proteins, fusion of SpyParts had little influence on both the level of protein retained within the cell and the secreted protein yield compared to the native XynA protein. By contrast, significantly increased levels of T-Xyn-C fusion protein are detected within the cellular fraction in the form of higher molecular weight species. The electrophoretic mobility of these species correspond to polymers of T-Xyn-C and their presence is not detected with a mutated version of $\mathrm{T}$ $\mathrm{Xyn}-\mathrm{C}$ in which the SpyTag-SpyCatcher conjugation reaction is prevented, suggesting a small fraction of the expressed T-Xyn-C protein polymerizes within the cell impeding secretion. However, the majority of expressed $\mathrm{T}$-Xyn-C protein is secreted, with yields comparable to XynA, T-Xyn-T and CXyn-C (Figure 1C and 1D).

To verify the activity of the secreted SpyTag and SpyCatcher motifs, we first purified the His ${ }_{6}$-tagged T-Xyn-T and C-Xyn-C proteins from B. subtilis culture supernatant using immobilized metal ion affinity chromatography (IMAC) (Supplementary Figure S4). Purified proteins were mixed (Figure 2A) and analyzed by Western blot (Figure 2B). Immediately upon mixing, covalently conjugated polymeric species were formed (Figure 2B) indicating that SpyTag and SpyCatcher were functional. After longer periods of incubation, the majority of monomers were converted to a polymeric form (Supplementary Figure S5).

To determine whether SpyTag and SpyCatcher were active under coculture, strains expressing T-Xyn-T and C-Xyn-C were grown alone or together and supernatant samples analyzed by Western blot (Figure 2C). A species with mobility correspond- ing to a dimer was detected after $2 \mathrm{~h}$ of coculture (Figure 2C), indicating that SpyTag and SpyCatcher are indeed functional under coculture conditions. Detection of polymeric species over longer periods of coculture was visible, but hampered by inherent proteolysis from the two extracellular proteases native to B. subtilis WB800N and by smearing of bands at higher molecular weights (Supplementary Figure S6).

To verify that the secreted T-Xyn-T and C-Xyn-C proteins were able to conjugate under coculture, we purified $\mathrm{His}_{6}$-tagged species from the supernatant of a coculture of strains expressing both T-Xyn-T and C-Xyn-C and their approximate molecular weights determined through size exclusion chromatographymultiangle light scattering (SEC-MALS) analysis (Supplementary Figure S7). Consistent with our previous observations, the major species present (60.9\%) exhibited a molecular weight corresponding to a T-Xyn-T and C-Xyn-C dimer. In addition, larger oligomer species were also detected as a minor fraction of the total protein (17.8\%).

Engineering XynA Thermotolerance by SpyRing Cyclization. To demonstrate the utility of this technique for protein engineering, we tested the ability of the SpyTagSpyCatcher reaction to improve the thermotolerance of XynA through SpyRing cyclization following secretion. Protein cyclization by linkage of the $\mathrm{N}$ - and C-termini has been shown to increase the ability of enzymes to tolerate exposure to high temperatures - a highly desirable trait for many industrial enzymes-and can be achieved through a number of methods. ${ }^{47-50}$ The SpyRing system works through fusion of the SpyTag and SpyCatcher respectively at the $\mathrm{N}$ - and Ctermini of a protein, leading to covalent cyclization that dramatically improves the ability of globular proteins to refold to native structures following exposure to high temperatures. ${ }^{51}$ 


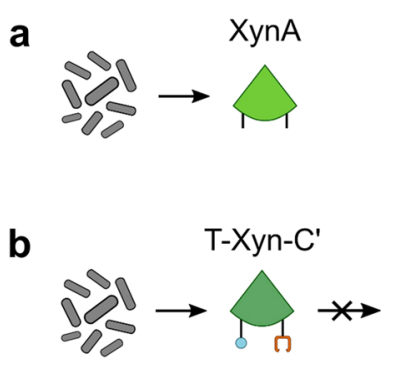

e
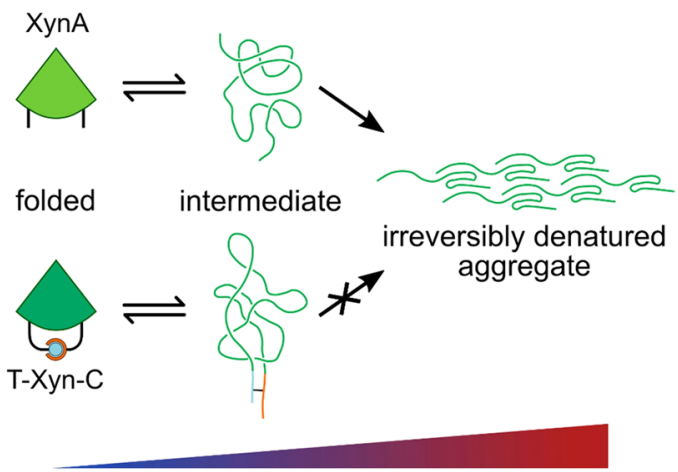

temperature

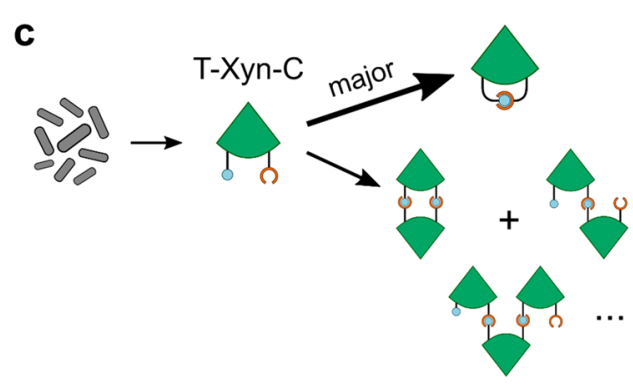

f
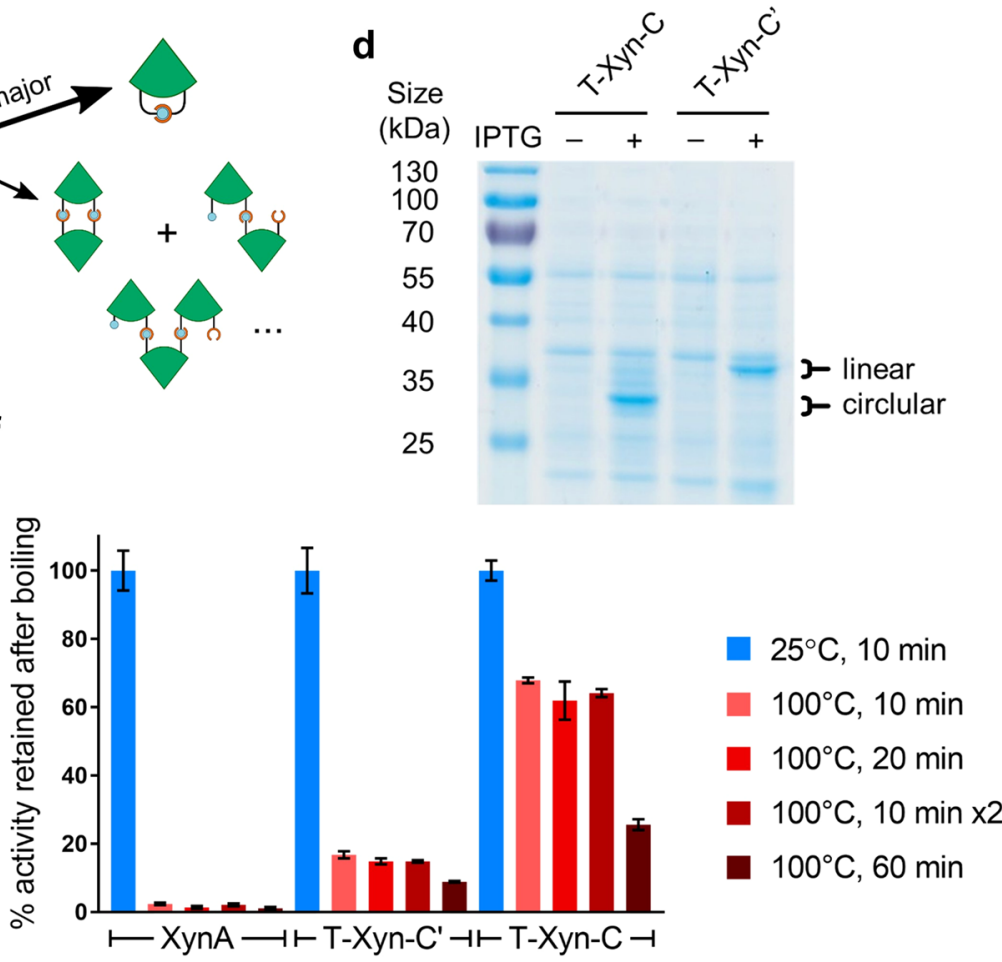

Figure 3. SpyRing cyclization confers XynA thermotolerance. Strains expressing XynA (a), the mutant SpyTag-XynA-SpyCatcher ${ }^{\mathrm{E} 77 \mathrm{Q}}$ (T-Xyn-C') (b), and SpyTag-XynA-SpyCatcher (T-Xyn-C) (c) were created. The T-Xyn-C protein is able to cyclize through SpyRing cyclization. (d) Comparison of the electrophoretic mobility of T-Xyn-C and T-Xyn-C' proteins by SDS-PAGE with Coomassie staining (expected molecular mass $\sim 35 \mathrm{kDa}$ ). A clear difference in electrophoretic mobility of the two proteins is seen, consistent with covalent cyclization of T-Xyn-C. (e) SpyRing cyclization works by covalently conjugating the $\mathrm{N}$ and $\mathrm{C}$-termini of a globular protein. Upon boiling, the folded protein begins to unfold. The SpyRing system is believed to prevent the irreversible transition of partially unfolded intermediates to denatured aggregates and therefore enable refolding when the temperature is lowered. (f) Culture supernatants from strains expressing XynA, T-Xyn- $\mathrm{C}^{\prime}$ and T-Xyn-C were subjected to a variety of high-temperature programs and subsequently assayed for xylanase activity. The T-Xyn-C protein shows dramatically increased tolerance to a variety of high temperature programs compared to XynA and T-Xyn-C'. Samples were analyzed in triplicate, data represent the mean \pm 1 SD.

While protein cyclization methods, such as the SpyRing system, have been previously shown to improve the thermotolerance of enzymes expressed intracellularly, ${ }^{50}$ programmable secretion of thermotolerant enzymes offers a new route to further decrease the costs of industrial scale production.

In addition to strains secreting the full length XynA and T$\mathrm{Xyn}-\mathrm{C}$ proteins, we engineered a strain to secrete a protein bearing the mutated SpyCatcher ${ }^{\mathrm{E77Q}}\left(\mathrm{C}^{\prime}\right)$ unable to form the covalent isopeptide linkage with the SpyTag, ${ }^{18}$ T-Xyn- ${ }^{\prime}$ (Figure $3 \mathrm{~A}-\mathrm{C}$ ). Due to the close proximity of the $\mathrm{N}$ - and $\mathrm{C}$ termini of XynA (within $1 \mathrm{~nm}$, Supplementary Figure S1) we anticipated that the SpyTag and SpyCatcher of the T-Xyn-C protein would be capable of reacting intramolecularly to cyclize XynA. While competing polymerization reactions are also possible (Figure 3C), we expected cyclization to be the major product, as seen with other SpyRing cyclizations, ${ }^{26}$ particularly since the concentration of the T-Xyn-C protein is relatively low in the culture medium.

To confirm cyclization, which is known to perturb the mobility of proteins during gel electrophoresis, ${ }^{26}$ we compared the electrophoretic mobility of T-Xyn-C to that of the mutant T-Xyn-C'. Consistent with SpyRing cyclization, the T-Xyn-C and T-Xyn-C' proteins exhibited substantially different mobilities under gel electrophoresis (Figure 3D and Supplementary Figures S3B and S4). To next determine whether SpyRing cyclization confers thermotolerance to XynA by preventing irreversible aggregation (Figure $3 \mathrm{E}$ ) we subjected supernatant samples from cultures secreting the native $\mathrm{XynA}$,
T-Xyn-C' and T-Xyn-C proteins to a variety of hightemperature conditions. After cooling to $4{ }^{\circ} \mathrm{C}$ these samples were then assayed for xylanase activity (Figure 3F). All supernatants exhibited similar levels of xylanase activity following incubation at $25{ }^{\circ} \mathrm{C}$ (Supplementary Figure S8). However, following exposure to high-temperature conditions only supernatants containing T-Xyn-C retained substantial levels of xylanase activity (Figure $3 \mathrm{~F}$ ). After exposure to $100{ }^{\circ} \mathrm{C}$ for $10 \mathrm{~min}, \mathrm{~T}-\mathrm{Xyn}-\mathrm{C}$ retained $67.9 \% \pm 0.9$ of its xylanase activity in contrast to negligible activity $(2.4 \% \pm 0.3)$ for XynA, and a similar protective effect was also seen across a variety of other high-temperature programs. Consistent with previous studies, $^{26}$ a mild protective effect was also observed for the mutant control T-Xyn- $\mathrm{C}^{\prime}$. This is likely due to the relatively strong, noncovalent interactions between SpyTag and SpyCatcher mutants. ${ }^{18}$

Owing to its ease of implementation and the availability of guidelines for its design, ${ }^{51}$ the SpyRing system is an attractive tool for improving the stability of enzymes. The SpyRing cyclization system has previously been harnessed to improve the thermotolerance of a number of intracellularly expressed enzymes with industrial relevance. ${ }^{27,28}$ However, since extracellular production of proteins for biotechnology vastly improves cost-effectiveness, our strategy offers a novel, attractive approach to the production and stabilization of industrially relevant enzymes. Notably, xylanases with improved thermal stability are of great interest to industry, offering an eco-friendly alternative to the chemicals used in the paper pulp 

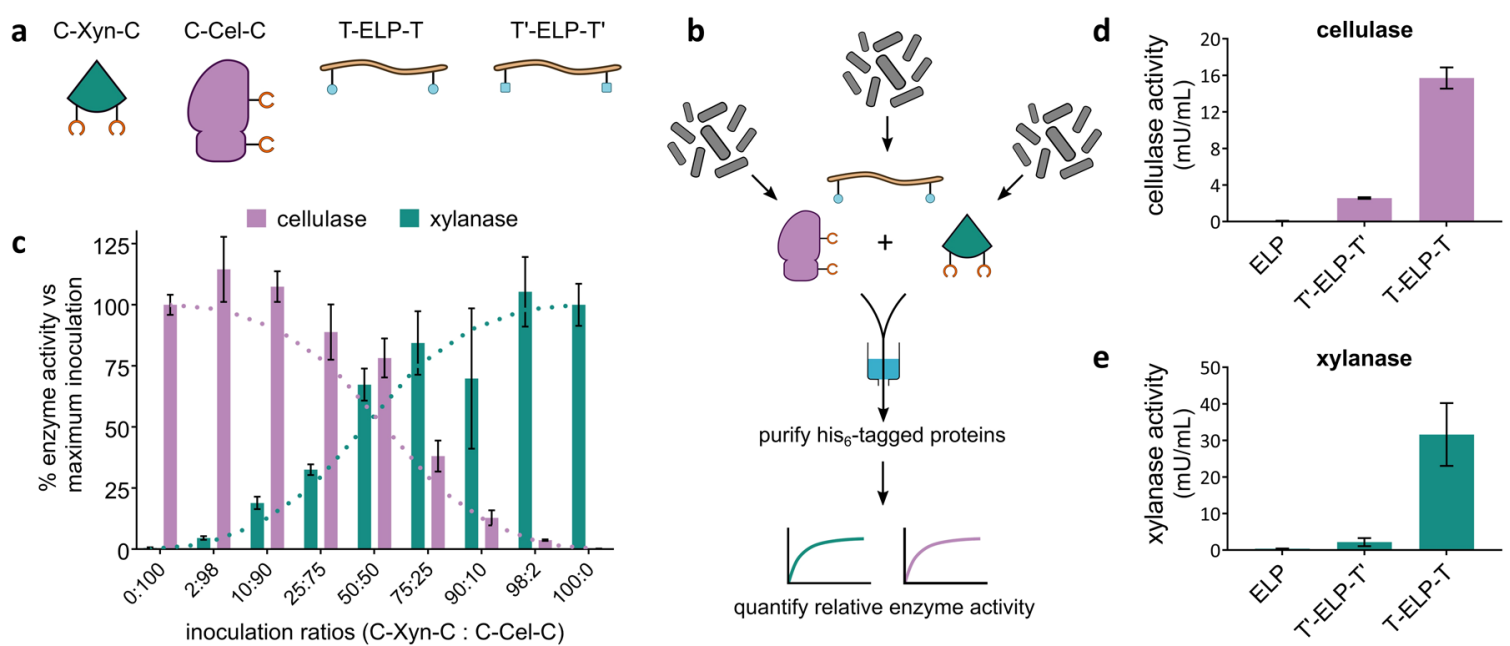

Figure 4. Tuning the composition of a protein-protein conjugate. (a) The four recombinant proteins used here: SpyCatcher-XynA-SpyCatcher lacking a C-terminal $\mathrm{His}_{6}$ tag $(\mathrm{C}-\mathrm{Xyn}-\mathrm{C})$, SpyCatcher-CelA-SpyCatcher lacking a C-terminal His 6 tag (C-Cel-C), SpyTag-ELP $20-24-$ SpyTag-His $_{6}(\mathrm{~T}$ ELP-T) and SpyTag ${ }^{\mathrm{DA}}-\mathrm{ELP}_{20-24}-\mathrm{SpyTag}^{\mathrm{DA}}-\mathrm{His}_{6}\left(\mathrm{~T}^{\prime}-\mathrm{ELP}-\mathrm{T}^{\prime}\right)$. Molecular weights of each species are also given (calculated assuming removal of $\mathrm{N}-$ terminal signal peptides). (b) Schematic illustrating the copurification experiment. (c) By modulating the proportion of cells expressing the C-Xyn-C (teal dotted line) inoculated compared to the proportion of cells expressing the C-Cel-C (lilac dotted line) inoculated, the relative levels of xylanase and cellulase activities (represented by the teal and lilac bars, respectively) copurified with T-ELP-T could be tuned across a variety of different inoculation ratios (samples prepared in triplicate, data represent the mean $\pm 1 \mathrm{SD}$ ). The $y$-axis plots percentage of enzyme activity calculated relative to the "maximum activity"-i.e., that detected from cocultures inoculated with $100 \%$ of the strain expressing the C-Xyn-C or C-Cel-C protein. Copurification of cellulase (d) and xylanase (e) activity was repeatable and dependent on the SpyTag-SpyCatcher reaction, as copurification sharply decreased when performed with an ELP construct lacking SpyTags (ELP) or with mutated SpyTags ( $\mathrm{T}^{\prime}$-ELP-T'). Samples prepared in triplicate, data represent the mean $\pm 1 \mathrm{SD}$.

bleaching process ${ }^{52}$ and as an additive to improve animal feed digestibility. ${ }^{53}$ And further, B. subtilis naturally secretes a number of other enzymes with industrial uses, including amylases, proteases and lipases.

A Modular Method for Extracellular Protein-Protein Conjugation from Cellular Consortia. Having demonstrated secretion and conjugation of $\mathrm{XynA}$ fusion proteins, we next looked to exploit our approach to conjugate alternative proteins of biotechnological interest from engineered cellular consortia. To facilitate assembly of plasmid constructs, we first designed a Golden Gate assembly system (Supplementary Figure S9A). This strategy allowed simple, one-step assembly of ORFs encoding an N-terminal signal peptide for secretion, an upstream SpyPart, a user-defined protein of interest and a Cterminal $\mathrm{His}_{6}$-tagged SpyPart. Parts were initially cloned into entry vectors from which they can be verified, stocked and reused for future assemblies (Supplementary Figure S9B). Stocked parts were then assembled directly into the pHT01 IPTG-inducible expression vector ready for use in B. subtilis.

Using this system, we created a series of plasmid constructs for secretion of recombinant proteins based on a second native B. subtilis enzyme, the endocellulase, CelA (Supplementary Figure S10). Like xylanases, cellulases have attracted interest in variety of industrial contexts, notably for their ability to degrade plant biomass, a sustainable potential feedstock for biocommodity production. ${ }^{54,55}$ In fact, creating multienzyme complexes of synergistic plant biomass-degrading enzymes such as CelA and XynA, has previously been shown to enhance the degradation of complex cellulosic substrates. ${ }^{56}$ As with XynA, we found that SpyParts could be fused to the $\mathrm{N}$ - and C-termini of CelA without disrupting secretion, directed by the native CelA secretion signal peptide (Supplementary Figure S10B and S10C) or enzyme activity (Supplementary Figure S10D). Additionally, fusion of SpyParts to CelA had no effect on the levels of protein retained within the cell (Supplementary Figure S10E). Interestingly, in contrast to T-Xyn-C, the T-Cel-C protein did not appear to be retained within the cell due to selfpolymerization. Further, these SpyParts were active and directed covalent linkage of XynA and CelA fusion proteins under coculture to form protein-protein conjugates (Supplementary Figure S11).

The ability to colocalize cooperative enzymes-ones that act in concert on a single substrate or in a pathway-has been shown to improve metabolic fluxes and is consequently a useful approach in metabolic engineering. ${ }^{7,8}$ Indeed, this is an strategy employed in nature; many bacteria that metabolize plant biomass do so by producing large, extracellular multiprotein complexes known as cellulosomes that consist of multiple synergistically acting enzymes. ${ }^{57}$ Notably, in efforts to engineer recombinant microbes capable of growth on plant biomass, two- and three-protein "designer-cellulosomes" have previously been assembled in vitro and in vivo by coculturing proteinsecreting bacterial strains through the cohesin-dockerin interaction, ${ }^{58,59}$ a noncovalent protein-protein interaction. ${ }^{60}$ However, in contrast to the cohesin-dockerin system, the covalent nature of SpyTag-SpyCatcher-based protein conjugation offers significant advantages for application in wider range of scenarios, as it improves the stability of complexes and removes the requirement for native protein folding.

Another potential area of use for this approach is in the assembly of protein biomaterials; the SpyTag-SpyCatcher reaction has been previously exploited in vitro to functionalize amyloid protein biofilms and to polymerize protein hydrogel materials. ${ }_{5,6,23-25}$ Therefore, to demonstrate the compatibility of heterologous biomaterial proteins with our system, we created a plasmid construct for expression and secretion of an elastin-like polypeptide (ELP) fused to SpyParts. The ELP used here, $\mathrm{ELP}_{20-24}$, is a short $10 \mathrm{kDa}$ polypeptide derived from 
human tropoelastin, consisting of one hydrophilic domain flanked by two hydrophobic domains. ${ }^{61}$ Owing to its short size, $\mathrm{ELP}_{20-24}$, does not undergo coacervation-an ELP-specific form of phase separation- under conditions used here.

Three fusion proteins based on $\mathrm{ELP}_{20-24}$ were generated, each with an $\mathrm{N}$-terminal signal peptide from the B. subtilis $\mathrm{SacB}$ protein (which provided the good secretion yields during initial testing) and a $\mathrm{C}$-terminal $\mathrm{His}_{6}$ tag. The first construct, ELP, consisted of $\mathrm{ELP}_{20-24}$ alone, lacking any SpyParts. The second construct, T-ELP-T, consisted of the ELP protein fused to upstream and downstream SpyTags. Lastly, a mutated version of T-ELP-T was generated in which the isopeptide bondforming aspartate residue of each SpyTag was mutated to alanine $\left(\mathrm{T}^{\prime}\right.$-ELP- $\left.\mathrm{T}^{\prime}\right)$, preventing covalent conjugation with SpyCatcher $^{18}$ (Supplementary Figure S12A and Figure 4A). Each of these proteins was well-expressed and secreted, although significant amounts of all three proteins were retained in the cellular fraction (Supplementary Figure S12B). In addition, plasmids expressing the $\mathrm{C}-\mathrm{Xyn}-\mathrm{C}$ and $\mathrm{C}-\mathrm{Cel}-\mathrm{C}$ proteins were also modified to remove their $\mathrm{C}$-terminal $\mathrm{His}_{6}$ tags.

Strains expressing T-ELP-T and the mutant $\mathrm{T}^{\prime}$-ELP-T' $\mathrm{T}^{\prime}$ were then cocultured with strains expressing the C-Xyn-C and CCel-C proteins. Supernatant samples from monocultures of each of the strains and from three-strain cocultures were analyzed by Western blot with an anti-His ${ }_{6}$ antibody (Supplementary Figure S12C). The T-ELP-T and the mutant $\mathrm{T}^{\prime}$-ELP-T' $\mathrm{T}^{\prime}$ proteins were well-expressed and secreted. When cultured together with the $\mathrm{C}-\mathrm{Xyn}-\mathrm{C}$ and $\mathrm{C}-\mathrm{Cel}-\mathrm{C}$ proteins, the mobility of the mutant $\mathrm{T}^{\prime}$-ELP-T' $\mathrm{T}^{\prime}$ was unaffected, whereas almost all of the secreted T-ELP-T protein was incorporated into dimeric and trimeric species (Supplementary Figure S12C and S12D), verifying conjugation by the Spy system.

In both the two-protein and three-protein coculture conjugations demonstrated here, the major products formed are dimer species, along with a minority of oligomer species (Supplementary Figures S11E and S12D). For specific applications, it will be preferable to precisely control the multimeric state and topology of conjugates formed. Following design rules from in vitro studies, our modular toolkit could therefore be adapted for user-defined extracellular self-assembly of dimers, ${ }^{18}$ circular, tadpole and star oligomers, ${ }^{19}$ catenanes ${ }^{21}$ and polymers. ${ }^{22,24}$

Tuning Conjugation through Consortia Composition. A key advantage of engineering cellular consortia to carry out a biological process, is that the balance between different subprocesses can be tuned simply by tuning the relative productivity of different strains within the coculture. To demonstrate this, we set out to tune the relative amounts of C-Xyn-C and C-Cel-C conjugated to T-ELP-T, simply by tuning the relative inoculation ratios of the producer strains in three-strain cocultures. To quantify the relative amounts of $\mathrm{C}$ Xyn-C and C-Cel-C conjugated to T-ELP-T, we performed copurifications using the $\mathrm{C}$-terminal $\mathrm{His}_{6}$ tag fused to ELP proteins. As outlined in Figure $4 \mathrm{~B}$, following three-strain coculture growth, $\mathrm{His}_{6}$-tagged ELP proteins were isolated from the culture supernatant by IMAC purification, and any SpyTagSpyCatcher conjugated proteins were copurified along with them while unbound proteins were washed off. The relative levels of C-Xyn-C and C-Cel-C conjugated to T-ELP-T were then quantified via enzyme activity assays.

We performed several three-strain cocultures in which the inoculum volume of the T-ELP-T expressing strain was fixed and the inoculation proportions of C-Xyn-C and C-Cel-C expressing strains varied. Enzyme activity was detected in all purified fractions, demonstrating the formation of functional protein conjugates (Figure 4C). We found that the proportions of CelA and XynA proteins incorporated into the extracellular protein-protein conjugates could be finely tuned simply by adjusting the proportions of the strains in the initial inoculations (Figure 4C). Furthermore, the relative enzyme activities of these complexes matched the relative inoculation proportions closely over a range of conditions. Additional copurifications with two negative control strains: a strain expressing the mutant $\mathrm{T}^{\prime}$-ELP-T ${ }^{\prime}$ only capable of noncovalent binding and a strain expressing secreted ELP lacking SpyTags, verified that the conjugation between all three proteins in the culture medium was specifically SpyTag-SpyCatcher-mediated as both controls showed dramatically reduced cellulase (Figure 4D) and xylanase (Figure 4E) levels. We thus verified our ability to tune the relative proportions of XynA and CelA incorporated into protein-protein conjugates simply by tuning their relative inoculation ratios.

This system thus offers a simple way to both assemble functional protein-protein conjugates and to fine-tune their properties. This approach could be useful in any scenario in which the proportions of individual components of proteinprotein conjugates influences the desired functions. For instance, when colocalizing co-operative enzymes to improve flux through a metabolic pathway-as with the previously mentioned "designer cellulosomes"-tuning enzyme proportions may enable improved yields by increasing the levels of enzymes catalyzing rate-limiting steps or decreasing the levels of enzymes producing toxic pathway intermediates.

\section{CONCLUSION}

Here we have demonstrated the feasibility and utility of combining protein secretion with SpyTag-SpyCatcher-mediated protein conjugation. We first coupled SpyRing cyclization with protein secretion, enabling one-step extracellular production and stabilization of the endoxylanase, XynA. Additionally, we applied our method to engineer extracellular production of self-assembling protein-protein conjugates from cellular consortia. Our approach allows the relative proportions of proteins incorporated into protein-protein conjugates to be fine-tuned simply by varying their relative inoculation ratios in cocultures, rather than requiring any additional genetic engineering such as promoter swapping. We have therefore shown, for the first time, that the SpyTag-SpyCatcher system can be deployed extracellularly in vivo and utilized in cocultures. We also showed that our system could be used to direct ELP secretion from $B$. subtilis and that an industrially relevant mesophilic enzyme could gain significant thermotolerance via spontaneous self-conjugation upon secretion.

Beyond the work presented here, the productivity of different strains within cocultures could be further controlled by coupling expression with additional genetic circuits, such as inducible switches and quorum sensing systems. ${ }^{62}$ Indeed, these tools have been previously harnessed within cellular consortia to program temporal and spatial control over monomer patterning within amyloid fibrils. ${ }^{5}$ In addition, transferring the strategy to alternative secretion hosts-such as the yeasts Saccharomyces cerevisiae and Pichia pastoris-would enable the secretion of a much broader range of heterologous proteins, relieving the need for compatibility with B. subtilis. As our approach is modular in design there is also great scope for 
integrating further components to broaden potential applications, such as alternative functional components or biological protein conjugation methods. ${ }^{20,60,63,64}$ Lastly, while the work here focuses exclusively on bivalent proteins-those possessing two SpyParts-incorporating additional SpyParts into fusion proteins could facilitate the formation of extended, branching polymeric networks and hydrogels. ${ }^{22,24}$

Programming protein conjugation and self-assembly within the extracellular environment offers great promise in the effort to generate novel industrial enzymes, multiprotein complexes and biological materials: improving production cost-effectiveness, reducing cellular burden and toxicity and enabling patterning and tunability through engineered cellular consortia. The modular approach described here therefore offers a platform for the development of biotechnological products to meet real-world challenges.

\section{METHODS}

Strains and Plasmids. Bacterial plasmids and strains used in this study are listed in Supplementary Table S1 and Supplementary Table S2, respectively. Both B. subtilis and E. coli were grown in LB medium or $2 \times Y \mathrm{YT}$ medium at $37^{\circ} \mathrm{C}$ under aeration. In all instances media were supplemented with appropriate antibiotics at the following concentrations for E. coli: ampicillin $100 \mu \mathrm{g} \mathrm{mL}^{-1}$, chloramphenicol $34 \mu \mathrm{g} \mathrm{mL}^{-1}$, kanamycin $50 \mu \mathrm{g} \mathrm{mL} \mathrm{m}^{-1}$. For B. subtilis, media were supplemented with $5 \mu \mathrm{g} \mathrm{mL}^{-1}$ chloramphenicol.

Plasmid Construction. All plasmids constructed in this study were constructed using standard cloning techniques. Oligonucleotides were obtained from IDT. Restriction endonucleases, Phusion-HF DNA polymerase and T7 DNA ligase were obtained from NEB. Unless stated, all plasmids were transformed into $E$. coli turbo (NEB) for amplification and verification before transforming into B. subtilis WB800N for protein expression and secretion. All constructs were verified by restriction enzyme digestion and Sanger sequencing (Source Bioscience). Amino acid sequences of protein parts used in this study are given in Supplementary Table S3.

To create the pHT01-xynA-His 6 construct, the native B. subtilis xynA ORF was amplified from the genome of B. subtilis 168 by colony PCR. Oligonucleotides were designed to introduce a C-terminal $\mathrm{His}_{6}$ tag as well as upstream $\mathrm{BamHI}$ and downstream AatII restriction enzyme sites. The amplified xynA-His $_{6}$ ORF and pHT01 backbone were digested with BamHI and AatII and gel purified and T4-ligated.

Using pHT01-xynA-His6 as a starting point, Golden Gate assembly was used to construct $\mathrm{pHT} 01-\mathrm{xynA}_{\mathrm{SP}}$-SpyTag-xynA-

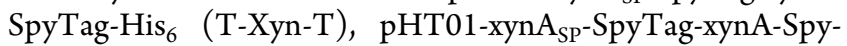
Catcher-His $_{6}$ (T-Xyn-C) and pHT01-xynA $\mathrm{SP}_{-}$-SpyCatcherxynA-SpyCatcher-His $_{6}$ (C-Xyn-C). Two versions of the SpyCatcher were synthesized by GeneArt (Life Technologies). A set of SpyCatcher-coding sequences codon-optimized for B. subtilis were created and the two most divergent sequences chosen (this was to reduce the risk of recombination within constructs containing two copies of the SpyCatcher). Two versions of the SpyTag were codon-optimized in the same manner and created from overlapping oligonucleotides. Golden Gate assemblies of gel purified PCR products using BsaI were performed as described. ${ }^{65}$ SpyTag and/or SpyCatcher sequences were introduced between the xynA signal peptide $\left(x_{\mathrm{SP}} \mathrm{A}_{\mathrm{SP}}\right)$ and xynA enzyme and between the xynA enzyme and $\mathrm{His}_{6}$ tag. In each instance, $4 \mathrm{bp}$ overhangs were incorporated into glycine-serine (GS) linkers. The backbone was amplified in two halves to allow mutation (and therefore removal) of an unwanted BsaI site in the AmpR cassette.

The pHT01-xynA $_{\mathrm{SP}}$-SpyTag-xynA-SpyCatcher ${ }^{\mathrm{E} 77 \mathrm{Q}}-\mathrm{His}_{6}$ (TXyn- $C^{\prime}$ ) mutant construct was created using $\mathrm{pHT}^{-} \mathrm{xyn}_{\mathrm{SP}^{-}}$ SpyTag-xynA-SpyCatcher-His ${ }_{6}(\mathrm{~T}-\mathrm{Xyn}-\mathrm{C})$ as a template. We used BsaI Golden Gate assembly based mutagenesis to mutate the catalytic glutamate of SpyCatcher to glutamine.

To suit our cloning needs we created a modular DNA assembly toolkit based on Golden Gate assembly (Supplementary Figure S9A). Four separate ORF parts were defined: a signal peptide part, an upstream SpyPart, a central protein of interest part and a downstream SpyPart. Each position was defined by the sequence of specific $4 \mathrm{bp}$ overhangs generated by BsaI digestion upstream and downstream of the part. Where fewer than four ORF parts are desired in the final construct, the 4 bp overhangs can be modified accordingly. ORF parts were cloned into a Golden Gate assembly part vector, pYTK001, where they were sequence-verified and stocked for subsequent assemblies. Stocked parts used in this study are summarized in Supplementary Figure S9B, their sequences given in Supplementary Table S4 and are available from Addgene.

We also created an entry vector derived from pHT01, called pCG004, itself assembled by BsaI Golden Gate assembly. The pHT01 backbone was amplified by PCR-again in two halves to allow removal of the unwanted BsaI site-and a dropout part introduced downstream of the $\mathrm{P}_{\text {grac }}$ promoter and upstream of the terminator. The dropout part consists of a constitutive GFP mut $3 b^{66}$ expression cassette flanked by BsaI restriction sites. Successful Golden Gate assembly will result in removal of the GFP expression cassette and therefore visual (green-white) screening of transformants. The GFP expression cassette was created using the $P_{\text {veg }}$ promoter and spoVG RBS, specifically chosen for their activity in both E. coli and B. subtilis-and therefore allowing transformation of Golden Gate assemblies into either strain.

We used our Golden Gate assembly system to construct

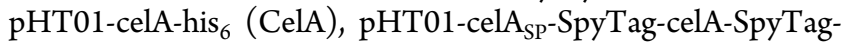
$\mathrm{His}_{6}$ (T-Cel-T), pHT01-celA $\mathrm{SP}$-SpyTag-celA-SpyCatcher-His ${ }_{6}$ (T-Cel-C) and pHT01-celA $\mathrm{SP}-$ SpyCatcher-celA-SpyCatcher$\mathrm{His}_{6}$ (C-Cel-C). To minimize the size of these constructs we used SpyCatcher $\Delta \mathrm{N} 1 \Delta \mathrm{C} 2$, which has superfluous amino acids trimmed from its $\mathrm{N}$ - and $\mathrm{C}$-termini ${ }^{67}$ (mSpyCatcher). Since repeated attempts to clone the $\mathrm{pHT} 01-\mathrm{celA}_{\mathrm{SP}_{\mathrm{S}}}$-SpyCatcher-celASpyCatcher-His $_{6}$ (C-Cel-C) plasmid into E. coli resulted in identical mutations of the upstream SpyCatcher, it was cloned directly into B. subtilis WB800N and sequence-verified. We also used our Golden Gate assembly system to construct pHT01$\mathrm{sacB}_{\mathrm{SP}}-\mathrm{ELP}_{20-24}-\mathrm{His}_{6}$ (ELP) and pHT01-sacB $\mathrm{SP}_{\mathrm{Spy}}$-SpagELP $_{20-24}$ SpyTag-His $_{6}$ (T-ELP-T).

BsaI Golden Gate assembly based mutagenesis was used to construct: the mutated pHT01-sacB $\mathrm{SP}-\mathrm{SpyTag}^{\mathrm{DA}}-\mathrm{ELP}_{20-24^{-}}$ SpyTag $^{\text {DA }}-\mathrm{His}_{6} \quad\left(\mathrm{~T}^{\prime}\right.$-ELP-T ${ }^{\prime}$ ) (from pHT01-sacB $\mathrm{SP}^{-}$-SpyTag$\mathrm{ELP}_{20-24}$-SpyTag-His ${ }_{6}$ ), the $\mathrm{His}_{6}$ tag-lacking $\mathrm{pHT}^{-} \mathrm{H}-\mathrm{xynA}_{\mathrm{SP}^{-}}$ SpyCatcher-xynA-SpyCatcher (from pHT01-xynA $\mathrm{SP}_{\mathrm{S}}$-SpyCatcher-xynA-SpyCatcher-His ${ }_{6}$ ) and the $\mathrm{His}_{6}$ tag-lacking pHT01celA $_{\mathrm{SP}}$-SpyCatcher-celA-SpyCatcher (from pHT01-celA $\mathrm{SP}-\mathrm{Spy}$ Catcher-celA-SpyCatcher-His ${ }_{6}$ ). Similar to the construct from which it was derived, pHT01-celA $\mathrm{SP}_{\mathrm{S}}$-SpyCatcher-celA-SpyCatcher repeatedly showed mutations when cloned into E. coli and so was instead cloned directly into B. subtilis WB800N and sequence-verified.

Protein Expression and Coculturing. In all instances, glycerol stocks of Bacillus subtilis strains were first spread onto 
selective LB plates from which single colonies were used to inoculate $5 \mathrm{~mL} 2 \times \mathrm{YT}$ liquid cultures. After $16 \mathrm{~h}$ of growth, strains were back-diluted $1 / 50$ into $5 \mathrm{~mL}$ of fresh $2 \times Y T$ medium. Where indicated, protein expression was induced with $1 \mathrm{mM}$ IPTG. Expression culturing was performed for between 2 and $8 \mathrm{~h}$, depending on the individual experiment. To collect secreted protein fractions, cultures were centrifuged at $3220 \mathrm{~g}$ for $10 \mathrm{~min}$ and supernatants harvested.

SDS-PAGE and Western Blotting. Since the concentration of proteins in the culture supernatant is relatively low, trichloroacetic acid (TCA) precipitation was performed to concentrate samples (by a factor of 10) prior to analysis by SDS-PAGE and Western blotting. Secreted proteins in the supernatant were precipitated by adding $100 \mu \mathrm{L}$ of $4{ }^{\circ} \mathrm{C} 100 \%$ TCA to $900 \mu \mathrm{L}$ of culture supernatant and incubating for $16 \mathrm{~h}$ at $4{ }^{\circ} \mathrm{C}$. Precipitated proteins were centrifuged at $16900 \mathrm{~g}$ for 10 min at $4{ }^{\circ} \mathrm{C}$, washed with $1 \mathrm{~mL}$ of ice-cold acetone, centrifuged again at $16900 \mathrm{~g}$ for $10 \mathrm{~min}$ at $4{ }^{\circ} \mathrm{C}$ and finally air-dried. Proteincontaining pellets were then resuspended in $90 \mu \mathrm{L}$ of $1 \times$ SDSPAGE sample buffer (0.2 M Tris- $\mathrm{HCl} \mathrm{pH} 6.8,2 \%$ SDS, $10 \%$ glycerol, $0.01 \%$ bromophenol blue $+2 \mathrm{mM}$ DTT) and boiled for $10 \mathrm{~min}$ at $100{ }^{\circ} \mathrm{C}$. To prepare cellular protein samples, 1 OD unit of culture was harvested by centrifuged at $16900 \mathrm{~g}$ for $10 \mathrm{~min}$. The cell pellet was resuspended in $150 \mu \mathrm{L}$ of lysis buffer (10 mM TRIS-HCl, 20\% sucrose, $10 \mathrm{mM}$ EDTA, $50 \mathrm{mM}$ $\mathrm{NaCl}, 2.5 \mathrm{mg} \mathrm{mL}^{-1}$ lysozyme, $\mathrm{pH} 8.1$ ) and incubated at $37{ }^{\circ} \mathrm{C}$ for $30 \mathrm{~min}$. After incubation, $37.5 \mu \mathrm{L}$ of $5 \times$ SDS-PAGE sample buffer was added and samples were boiled for $10 \mathrm{~min}$ at $100{ }^{\circ} \mathrm{C}$.

SDS-PAGE gels-with differing separating gel percentages depending on the size of proteins analyzed-were run as standard and proteins stained using SimplyBlue SafeStain (Thermo). Alternatively, proteins were transferred to a PVDF membrane for immunodetection using a mouse anti-His 6 primary antibody (BioLegend clone: J099B12) and an alkaline phosphatase-conjugated antimouse secondary antibody (Promega). Bound antibodies were detecting using a BCIP-NBT colorimetric kit (Life Technologies).

Enzyme Activity Assays. Assays for xylanase and cellulase activities were performed using the EnzChek Cellulase Substrate (Thermo) and EnzChek Ultra Xylanase Assay Kit (ThermoFisher). Substrate solutions were prepared according to the manufacturer's instructions. In both assays $50 \mu \mathrm{L}$ supernatant samples were pipetted into a Costar 96-well Cell Culture Plate (Corning) and $50 \mu \mathrm{L}$ substrate solutions added simultaneously with a multichannel pipet. Samples were immediately analyzed on a Synergy HT plate reader-both assays report enzyme activity through a fluorogenic substrate. All assays were performed at room temperature with biological triplicates. In order to calculate xylanase and cellulase enzyme activities, standard curves were prepared using known amounts of xylanase (T. lanuginosus Xylanase, Sigma X2753) and cellulase ( $T$. reseii Cellulase, Sigma C2730) enzymes. For standard curves and for actual samples, enzyme reaction rates were calculated from the gradient over the linear region of a graph plotting fluorescence AU over time. Where appropriate, enzyme activities were calculated using the standard curves shown in Supplementary Figure S13A and S13B.

Protein Purification. Protein purifications were performed using HisPur Ni-NTA Spin Columns (ThermoFisher), with 0.2 $\mathrm{mL}$ resin bed volume, according to the manufacturer's instructions. Prior to purification, $3 \mathrm{~mL}$ samples of culture supernatant were first mixed with a $10 \times$ concentrated equilibration solution (500 mM NaH $\mathrm{PO}_{4}, 2.15 \mathrm{M}$ Sodium
Chloride, $100 \mathrm{mM}$ imidazole, $\mathrm{pH} 8.0$ ) to enable efficient binding of His6-tagged proteins to the Ni-NTA resin. A total of $2 \mathrm{~mL}$ of supernatant was passed over the Ni-NTA resin in three batches of $666 \mu \mathrm{L}$, with each incubated with the resin for 15 min prior to collecting flow through. Three washes were performed with $666 \mu \mathrm{L}$ of wash buffer $\left(50 \mathrm{mM} \mathrm{NaH}_{2} \mathrm{PO}_{4}, 300\right.$ mM Sodium Chloride, $20 \mathrm{mM}$ imidazole, $\mathrm{pH}$ 8.0) followed by elution in $500 \mu \mathrm{L}$ of elution buffer $\left(50 \mathrm{mM} \mathrm{NaH}_{2} \mathrm{PO}_{4}, 300 \mathrm{mM}\right.$ Sodium Chloride, $250 \mathrm{mM}$ imidazole, $\mathrm{pH} 8.0$ ). All 10 core proteins in this study were purified in this way and the concentration of purified protein was quantified using Pierce BCA Protein Assay Kit (Thermo) according to the manufacturer's instructions, and is presented in Supplementary Figure S14.

SEC-MALS Sample Preparation. To prepare more concentrated purified protein required for SEC-MALS analysis, $5 \mathrm{~mL}$ seed cultures of strains expressing T-Xyn-T and C-Xyn-C were inoculated into $200 \mathrm{~mL} 2 \times \mathrm{YT}$ medium to a final $\mathrm{OD}_{600}=$ 0.1 and incubated at $37^{\circ} \mathrm{C}$. When an $\mathrm{OD}_{600} \sim 0.5$ was reached, protein expression was induced by the addition of IPTG to a final concentration of $1 \mathrm{mM}$. After a further $4 \mathrm{~h}$ incubation, the culture was centrifuged at $4000 \mathrm{~g}$ at $4{ }^{\circ} \mathrm{C}$ for $20 \mathrm{~min}$. The supernatant was removed and again centrifuged at $4000 \mathrm{~g}$ at 4 ${ }^{\circ} \mathrm{C}$ for $20 \mathrm{~min} .150 \mathrm{~mL}$ of clarified supernatant was harvested. To this, $16.7 \mathrm{~mL}$ of $10 \times$ equilibration buffer $(500 \mathrm{mM}$ $\mathrm{NaH}_{2} \mathrm{PO}_{4}, 2.15 \mathrm{M}$ Sodium Chloride, $100 \mathrm{mM}$ imidazole, pH8.0) was added. Ten $\mathrm{mL}$ of pre-equilibrated HisPur Ni-NTA resin (Thermo) was then added to the supernatant and incubated on ice with shaking for $1 \mathrm{~h}$. The resin was allowed to settle out on ice and $\sim 130 \mathrm{~mL}$ of supernatant removed by pipetting. The resin was then resuspended with the remaining liquid and transferred to a $10 \mathrm{~mL}$ Pierce Disposable Column (Thermo) and the supernatant eluted off the column. Three washes were performed with $10 \mathrm{~mL}$ of wash buffer $(50 \mathrm{mM}$ $\mathrm{NaH}_{2} \mathrm{PO}_{4}, 300 \mathrm{mM}$ Sodium Chloride, $20 \mathrm{mM}$ imidazole, $\mathrm{pH} 8.0$ ) followed by two $10 \mathrm{~mL}$ elutions with elution buffer ( 50 $\mathrm{mM} \mathrm{NaH}{ }_{2} \mathrm{PO}_{4}, 300 \mathrm{mM}$ Sodium Chloride, $250 \mathrm{mM}$ imidazole, $\mathrm{pH} 8.0$ ). Elution fractions were concentrated to $\sim 2 \mathrm{mg} \mathrm{mL}^{-1}$ using Pierce Protein Concentrator columns (10K MWCO, Thermo).

Enzyme Thermotolerance Assays. To assess the ability of different proteins to withstand boiling, supernatants samples were exposed to specified temperature programs using a ProFlex PCR System (ThermoFisher) thermal cycler. Following boiling, samples were cooled a rate of $3{ }^{\circ} \mathrm{C} / \mathrm{sec}$ to $4{ }^{\circ} \mathrm{C}$, reequilibrated to room temperature and assayed for xylanase activity. Data were presented as plots showing the accumulation of fluorescent product over time. In addition, reactions rates were calculated by taking gradient over the linear (early) region of the fluorescence-time plots. The percentage of enzyme activity retained after boiling was calculated by comparing reactions rates between samples subjected to $25^{\circ} \mathrm{C}$ for $10 \mathrm{~min}$ and samples subjected to $100{ }^{\circ} \mathrm{C}$ for $10 \mathrm{~min}$ (or otherwise stated).

Coculture Conditions, Copurifications, and Enzyme Assays. Two-strain cocultures were performed with strains expressing SpyTag-CelA-SpyTag-His ${ }_{6}$ and SpyCatcher-XynASpyCatcher proteins. Seed cultures in $2 \times Y T$ medium were grown for $16 \mathrm{~h}$ and used to inoculate cocultures. Inductions were performed by inoculating $5 \mathrm{~mL} 2 \times \mathrm{YT}$ medium containing $1 \mathrm{mM}$ IPTG with $50 \mu \mathrm{L}$ of each strain, or $100 \mu \mathrm{L}$ of each strain for monocultures. Supernatant samples were harvested after 6 
and $8 \mathrm{~h}$ of incubation at $37^{\circ} \mathrm{C}$ and analyzed by SDS-PAGE and Western blotting.

Three-strain cocultures were performed with strains expressing C-Xyn-C, C-Cel-C and various $\mathrm{ELP}_{20-24}$-containing proteins. In this instance triplicate seed cultures in $2 \times \mathrm{YT}$ medium were grown for $16 \mathrm{~h}$. Since seed cultures consistently reached similar optical densities $\left(\mathrm{OD}_{600}=4.5-5.5\right)$, identical inoculation volumes were used for each replicate during inductions.

To compare the ability of the T-ELP-T, the mutant T'-ELP$\mathrm{T}^{\prime}$ and the ELP proteins to copurify xylanase and cellulase activities, $40 \mu \mathrm{L}$ of each of the three strains were inoculated into $5 \mathrm{~mL} 2 \times \mathrm{YT}$ medium containing $1 \mathrm{mM}$ IPTG. After $8 \mathrm{~h}$ of incubation at $37{ }^{\circ} \mathrm{C}$ supernatants were harvested and analyzed by Western blotting using an anti-His ${ }_{6}$ antibody. In addition, IMAC purifications of $\mathrm{His}_{6}$-tagged proteins in the supernatant were performed as described above.

To test the ability to tune the composition of proteinprotein conjugates, a number of different three-strain cocultures were prepared in which the ratio of strains expressing the $\mathrm{C}$ Xyn-C and C-Cel-C proteins was varied. The T-ELP-Texpressing strain inoculation was fixed at $40 \mu \mathrm{L}$. The total inoculation volume of strains expressing the $\mathrm{C}-\mathrm{Xyn}-\mathrm{C}$ and $\mathrm{C}$ Cel-C proteins was fixed at $80 \mu \mathrm{L}$ and varied: $0 \%: 100 \%(0$ $\mu \mathrm{L}: 80 \mu \mathrm{L}), 2 \%: 98 \%(1.6 \mu \mathrm{L}: 78.4 \mu \mathrm{L}), 10 \%: 90 \%(8 \mu \mathrm{L}: 72 \mu \mathrm{L})$, 25\%:75\% (20 $\mu \mathrm{L}: 60 \mu \mathrm{L}), 50 \%: 50 \%(40 \mu \mathrm{L}: 40 \mu \mathrm{L}) 75 \%: 25 \%$ (60 $\mu \mathrm{L}: 20 \mu \mathrm{L}), 90 \%: 10 \%(72 \mu \mathrm{L}: 8 \mu \mathrm{L}), 98 \%: 2 \%(78.4 \mu \mathrm{L}: 1.6$ $\mu \mathrm{L})$ and $100 \%: 0 \%(80 \mu \mathrm{L}: 0 \mu \mathrm{L})$. After $8 \mathrm{~h}$ of incubation at 37 ${ }^{\circ} \mathrm{C}$ supernatants were harvested and, again, IMAC purifications of $\mathrm{His}_{6}$-tagged proteins in the supernatant were performed as described above.

Purified protein samples were analyzed by xylanase and cellulase activity assays to determine the relative levels of copurified protein. Reaction rates were calculated by determining the gradient of the linear region of the fluorescence-time plots. The "maximum activity" was defined as that detected from cocultures inoculated with $100 \%(80 \mu \mathrm{L})$ of the strain expressing the $\mathrm{C}-\mathrm{Xyn}-\mathrm{C}$ or $\mathrm{C}-\mathrm{Cel}-\mathrm{C}$ protein, and percentage activities were calculated on the basis of this value.

\section{ASSOCIATED CONTENT}

\section{S Supporting Information}

The Supporting Information is available free of charge on the ACS Publications website at DOI: 10.1021/acssynbio.6b00292.

Supplementary Figures: additional experimental data and illustrations of the design of protein and DNA parts; Supplementary Tables: list of plasmids, list of strains, list of protein parts including their amino acid sequences, list of Golden Gate assembly parts available from Addgene (PDF)

\section{AUTHOR INFORMATION}

\section{Corresponding Author}

*E-mail: t.ellis@imperial.ac.uk.

\section{ORCID 10}

Tom Ellis: 0000-0001-5392-976X

\section{Funding}

This work was funded by UK Engineering and Physical Sciences Research Council (EPSRC) awards EP/M002306/1 (TE), EP/J02175X/1 (CH and TE) and EP/N023226/1 $(\mathrm{MH})$, an Imperial College London President's Scholarship
(CG), and Marie Curie Initial Training Network ATRIEM (EC Project No. 317228).

\section{Notes}

The authors declare no competing financial interest.

\section{ACKNOWLEDGMENTS}

We are grateful to Dr. Carlos Bricio-Garberi and Dr. Olivier Borkowski for constant advice, discussions and suggestions. We thank Christopher Sauer and Rita Cruz for providing advice and guidance on B. subtilis biology and protein secretion, Dr. Christopher Schoene for advice regarding SpyRing cyclization, Dr. Alex Webb for providing protein expression strains and constructs, and Dr. Ciaran McKeown for performing the SECMALS experiment.

\section{REFERENCES}

(1) Hartwell, L. H., Hopfield, J. J., Leibler, S., and Murray, A. W. (1999) From molecular to modular cell biology. Nature 402, C47C52.

(2) Parmar, P. A., Chow, L. W., St-Pierre, J.-P., Horejs, C.-M., Peng, Y. Y., Werkmeister, J. A., Ramshaw, J. A. M., and Stevens, M. M. (2015) Collagen-mimetic peptide-modifiable hydrogels for articular cartilage regeneration. Biomaterials 54, 213-225.

(3) Minamihata, K., Yamaguchi, S., Nakajima, K., and Nagamune, T. (2016) Tyrosine Coupling Creates a Hyperbranched Multivalent Protein Polymer Using Horseradish Peroxidase via Bipolar Conjugation Points. Bioconjugate Chem. 27, 1348-1359.

(4) Vidal, G., Blanchi, T., Mieszawska, A. J., Calabrese, R., Rossi, C., Vigneron, P., Duval, J. L., Kaplan, D. L., and Egles, C. (2013) Enhanced cellular adhesion on titanium by silk functionalized with titanium binding and RGD peptides. Acta Biomater. 9, 4935-4943.

(5) Chen, A. Y., Deng, Z., Billings, A. N., Seker, U. O. S., Lu, M. Y., Citorik, R. J., Zakeri, B., and Lu, T. K. (2014) Synthesis and patterning of tunable multiscale materials with engineered cells. Nat. Mater. 13, $515-23$.

(6) Nguyen, P. Q., Botyanszki, Z., Tay, P. K. R., and Joshi, N. S. (2014) Programmable biofilm-based materials from engineered curli nanofibres. Nat. Commun. 5, 4945.

(7) Myhrvold, C., Polka, J. K., and Silver, P. A. (2016) Synthetic Lipid-Containing Scaffolds Enhance Production by Colocalizing Enzymes. ACS Synth. Biol. 5, 1396-1403.

(8) Giessen, T. W., and Silver, P. (2016) A catalytic nanoreactor based on in vivo encapsulation of multiple enzymes in an engineered protein nanocompartment. ChemBioChem 17, 1931-1935.

(9) Brune, K. D., Leneghan, D. B., Brian, I. J., Ishizuka, A. S., Bachmann, M. F., Draper, S. J., Biswas, S., and Howarth, M. (2016) Plug-and-Display: decoration of Virus-Like Particles via isopeptide bonds for modular immunization. Sci. Rep. 6, 19234.

(10) Thrane, S., Janitzek, C. M., Matondo, S., Resende, M., Gustavsson, T., de Jongh, W. A., Clemmensen, S., Roeffen, W., van de Vegte-Bolmer, M., van Gemert, G. J., Sauerwein, R., Schiller, J. T., Nielsen, M. A., Theander, T. G., Salanti, A., and Sander, A. F. (2016) Bacterial superglue enables easy development of efficient virus-like particle based vaccines. J. Nanobiotechnol. 14, 30.

(11) Liu, Z., Zhou, H., Wang, W., Tan, W., Fu, Y.-X., and Zhu, M. (2014) A novel method for synthetic vaccine construction based on protein assembly. Sci. Rep. 4, 7266.

(12) Kan, S.-H., Aoyagi-Scharber, M., Le, S. Q., Vincelette, J., Ohmi, K., Bullens, S., Wendt, D. J., Christianson, T. M., Tiger, P. M. N., Brown, J. R., Lawrence, R., Yip, B. K., Holtzinger, J., Bagri, A., CrippenHarmon, D., Vondrak, K. N., Chen, Z., Hague, C. M., Woloszynek, J. C., Cheung, D. S., Webster, K. A., Adintori, E. G., Lo, M. J., Wong, W., Fitzpatrick, P. A., LeBowitz, J. H., Crawford, B. E., Bunting, S., Dickson, P. I., and Neufeld, E. F. (2014) Delivery of an enzyme-IGFII fusion protein to the mouse brain is therapeutic for mucopolysaccharidosis type IIIB. Proc. Natl. Acad. Sci. U. S. A. 111, 14870-5. 
(13) Chen, X., Zaro, J. L., and Shen, W.-C. (2013) Fusion protein linkers: property, design and functionality. Adv. Drug Delivery Rev. 65, 1357-69.

(14) Yang, H., Liu, L., and Xu, F. (2016) The promises and challenges of fusion constructs in protein biochemistry and enzymology. Appl. Microbiol. Biotechnol. 100, 8273-8281.

(15) Albayrak, C., and Swartz, J. R. (2014) Direct polymerization of proteins. ACS Synth. Biol. 3, 353-62.

(16) Zhang, M., Lin, S., Song, X., Liu, J., Fu, Y., Ge, X., Fu, X., Chang, Z., and Chen, P. R. (2011) A genetically incorporated crosslinker reveals chaperone cooperation in acid resistance. Nat. Chem. Biol. 7, $671-7$.

(17) Hudak, J. E., Barfield, R. M., Dehart, G. W., Grob, P., Nogales, E., Bertozzi, C. R., and Rabuka, D. (2012) Synthesis of heterobifunctional protein fusions using copper-free click chemistry and the aldehyde tag. Angew. Chem., Int. Ed. 51, 4161-4165.

(18) Zakeri, B., Fierer, J. O., Celik, E., Chittock, E. C., Schwarz-Linek, U., Moy, V. T., and Howarth, M. (2012) Peptide tag forming a rapid covalent bond to a protein, through engineering a bacterial adhesin. Proc. Natl. Acad. Sci. U. S. A. 109, E690.

(19) Zhang, W.-B., Sun, F., Tirrell, D. a, and Arnold, F. H. (2013) Controlling macromolecular topology with genetically encoded SpyTag-SpyCatcher chemistry. J. Am. Chem. Soc. 135, 13988-97.

(20) Veggiani, G., Nakamura, T., Brenner, M. D., Gayet, R. V., Yan, J., Robinson, C. V., and Howarth, M. (2016) Programmable polyproteams built using twin peptide superglues. Proc. Natl. Acad. Sci. U. S. A. 113, 1202-7.

(21) Wang, X. W., and Zhang, W. B. (2016) Cellular Synthesis of Protein Catenanes. Angew. Chem., Int. Ed. 55, 3442-3446.

(22) Sun, F., Zhang, W.-B., Mahdavi, A., Arnold, F. H., and Tirrell, D. a. (2014) Synthesis of bioactive protein hydrogels by genetically encoded SpyTag-SpyCatcher chemistry. Proc. Natl. Acad. Sci. U. S. A. $111,11269$.

(23) Botyanszki, Z., Tay, P. K. R., Nguyen, P. Q., Nussbaumer, M. G., and Joshi, N. S. (2015) Engineered catalytic biofilms: Site-specific enzyme immobilization onto E. coli curli nanofibers. Biotechnol. Bioeng. 110, 2016-2024.

(24) Gao, X., Fang, J., Xue, B., Fu, L., and Li, H. (2016) Engineering Protein Hydrogels Using SpyCatcher-SpyTag Chemistry. Biomacromolecules 17, 2812-2819.

(25) Dorval Courchesne, N.-M., Duraj-Thatte, A., Tay, P. K. R., Nguyen, P. Q., and Joshi, N. S. (2016) Scalable Production of Genetically Engineered Nanofibrous Macroscopic Materials via Filtration. ACS Biomater. Sci. Eng., DOI: 10.1021/acsbiomaterials.6b00437.

(26) Schoene, C., Fierer, J. O., Bennett, S. P., and Howarth, M. (2014) SpyTag/SpyCatcher cyclization confers resilience to boiling on a mesophilic enzyme. Angew. Chem., Int. Ed. 53, 6101-4.

(27) Wang, J., Wang, Y., Wang, X., Zhang, D., Wu, S., and Zhang, G. (2016) Enhanced thermal stability of lichenase from Bacillus subtilis 168 by SpyTag/SpyCatcher-mediated spontaneous cyclization. Biotechnol. Biofuels 9, 79.

(28) Schoene, C., Bennett, S. P., and Howarth, M. (2016) SpyRing interrogation: analyzing how enzyme resilience can be achieved with phytase and distinct cyclization chemistries. Sci. Rep. 6, 1-12.

(29) Alves, N. J., Turner, K. B., Daniele, M. A., Oh, E., Medintz, I. L., and Walper, S. A. (2015) Bacterial Nanobioreactors-Directing Enzyme Packaging into Bacterial Outer Membrane Vesicles. ACS Appl. Mater. Interfaces 7, 24963-24972.

(30) Alves, N. J., Turner, K. B., Medintz, I. L., and Walper, S. A. (2016) Protecting enzymatic function through directed packaging into bacterial outer membrane vesicles. Sci. Rep. 6, 24866.

(31) Fierer, J. O., Veggiani, G., and Howarth, M. (2014) SpyLigase peptide-peptide ligation polymerizes affibodies to enhance magnetic cancer cell capture. Proc. Natl. Acad. Sci. U. S. A. 111, E1176-81.

(32) Lakshmanan, A., Farhadi, A., Nety, S. P., Lee-Gosselin, A., Bourdeau, R. W., Maresca, D., and Shapiro, M. G. (2016) Molecular Engineering of Acoustic Protein Nanostructures. ACS Nano 10, 73147322 .
(33) Bedbrook, C. N., Kato, M., Ravindra kumar, S., Lakshmanan, A., Nath, R. D., Sun, F., Sternberg, P. W., Arnold, F. H., and Gradinaru, V. (2015) Genetically Encoded Spy Peptide Fusion System to Detect Plasma Membrane-Localized Proteins In Vivo. Chem. Biol. 22, 11081121.

(34) Moon, H., Bae, Y., Kim, H., and Kang, S. (2016) Plug-andplayable fluorescent cell imaging modular toolkits using the bacterial superglue, SpyTag/SpyCatcher. Chem. Commun. 52, 14051-14054.

(35) Dovala, D., Sawyer, W. S., Rath, C. M., and Metzger, L. E. (2016) Rapid analysis of protein expression and solubility with the SpyTag-SpyCatcher system. Protein Expression Purif. 117, 44-51.

(36) Schloss, A. C., Liu, W., Williams, D. M., Kaufman, G., Hendrickson, H. P., Rudshteyn, B., Fu, L., Wang, H., Batista, V. S., Osuji, C., Yan, E. C. Y., and Regan, L. (2016) Fabrication of Modularly Functionalizable Microcapsules Using Protein-Based Technologies. ACS Biomater. Sci. Eng. 2, 1856.

(37) Peschke, T., Rabe, K. S., and Niemeyer, C. M. (2017) Orthogonal Surface Tags for Whole-Cell Biocatalysis. Angew. Chem., Int. Ed. 56, 1-5.

(38) Mergulhão, F. J. M., Summers, D. K., and Monteiro, G. a. (2005) Recombinant protein secretion in Escherichia coli. Biotechnol. Adv. 23, 177-202.

(39) Azam, A., Li, C., Metcalf, K. J., and Tullman-Ercek, D. (2016) Type III Secretion as a Generalizable Strategy for the Production of Full-Length Biopolymer-Forming Proteins. Biotechnol. Bioeng. 113, 18.

(40) Goers, L., Freemont, P., and Polizzi, K. M. (2014) Co-culture systems and technologies: taking synthetic biology to the next level. J. R. Soc., Interface 11, 20140065.

(41) Hays, S. G., Patrick, W. G., Ziesack, M., Oxman, N., and Silver, P. A. (2015) Better together: Engineering and application of microbial symbioses. Curr. Opin. Biotechnol. 36, 40-49.

(42) Zhou, K., Qiao, K., Edgar, S., and Stephanopoulos, G. (2015) Distributing a metabolic pathway among a microbial consortium enhances production of natural products. Nat. Biotechnol. 33, 377383.

(43) Brenner, K., You, L., and Arnold, F. H. (2008) Engineering microbial consortia: a new frontier in synthetic biology. Trends Biotechnol. 26, 483-9.

(44) Jones, J. A., Vernacchio, V. R., Sinkoe, A. L., Collins, S. M., Ibrahim, M. H. A., Lachance, D. M., Hahn, J., and Koffas, M. A. G. (2016) Experimental and computational optimization of an Escherichia coli co-culture for the efficient production of flavonoids. Metab. Eng. 35, 55-63.

(45) Harwood, C. R., and Cranenburgh, R. (2008) Bacillus protein secretion: an unfolding story. Trends Microbiol. 16, 73-79.

(46) van Dijl, J. M., and Hecker, M. (2013) Bacillus subtilis: from soil bacterium to super-secreting cell factory. Microb. Cell Fact. 12, 3.

(47) Scott, C. P., Abel-Santos, E., Wall, M., Wahnon, D. C., and Benkovic, S. J. (1999) Production of cyclic peptides and proteins in vivo. Proc. Natl. Acad. Sci. U. S. A. 96, 13638-13643.

(48) Trabi, M., and Craik, D. J. (2002) Circular proteins - no end in sight. Trends Biochem. Sci. 27, 132-138.

(49) Iwai, H., and Plu, A. (1999) Circular L-lactamase: stability enhancement by cyclizing the backbone. FEBS Lett. 459, 166-172.

(50) Waldhauer, M. C., Schmitz, S. N., Ahlmann-Eltze, C., Gleixner, J. G., Schmelas, C. C., Huhn, A. G., Bunne, C., Büscher, M., Horn, M., Klughammer, N., Kreft, J., Schäfer, E., Bayer, P. A., Krämer, S. G., Neugebauer, J., Wehler, P., Mayer, M. P., Eils, R., and Di Ventura, B. (2015) Backbone circularization of Bacillus subtilis family 11 xylanase increases its thermostability and its resistance against aggregation. Mol. BioSyst. 11, 3231-43.

(51) Schoene, C., Bennett, S. P., and Howarth, M. (2016) SpyRings Declassified: A Blueprint for Using Isopeptide-Mediated Cyclization to Enhance Enzyme Thermal Resilience. In Pept. Protein Enzym. Des., 1st ed., Elsevier Inc.

(52) Kumar, V., Marín-Navarro, J., and Shukla, P. (2016) Thermostable microbial xylanases for pulp and paper industries: 
trends, applications and further perspectives. World J. Microbiol. Biotechnol. 32, 1-10.

(53) Juturu, V., and Wu, J. C. (2012) Microbial xylanases: Engineering, production and industrial applications. Biotechnol. Adv. 30, 1219-1227.

(54) Kuhad, R. C., Gupta, R., and Singh, A. (2011) Microbial cellulases and their industrial applications. Enzyme Res. 2011, 280696.

(55) Zhang, X. Z., and Zhang, Y. H. P. (2010) One-step production of biocommodities from lignocellulosic biomass by recombinant cellulolytic Bacillus subtilis: Opportunities and challenges. Eng. Life Sci. 10, 398-406.

(56) Moraïs, S., Barak, Y., Caspi, J., and Hadar, Y. (2010) Cellulasexylanase synergy in designer cellulosomes for enhanced degradation of a complex cellulosic substrate. mBio 1, 3-10.

(57) Fontes, C. M. G. A., and Gilbert, H. J. (2010) Cellulosomes: Highly Efficient Nanomachines Designed to Deconstruct Plant Cell Wall Complex Carbohydrates. Annu. Rev. Biochem. 79, 655-681.

(58) Arai, T., Matsuoka, S., Cho, H.-Y., Yukawa, H., Inui, M., Wong, S.-L., and Doi, R. H. (2007) Synthesis of Clostridium cellulovorans minicellulosomes by intercellular complementation. Proc. Natl. Acad. Sci. U. S. A. 104, 1456-1460.

(59) Moraïs, S., Shterzer, N., Lamed, R., Bayer, E. A., and Mizrahi, I. (2014) A combined cell-consortium approach for lignocellulose degradation by specialized Lactobacillus plantarum cells. Biotechnol. Biofuels 7, 112.

(60) Stahl, S. W., Nash, M. A., Fried, D. B., Slutzki, M., Barak, Y., Bayer, E. A., and Gaub, H. E. (2012) Single-molecule dissection of the high-affinity cohesin-dockerin complex. Proc. Natl. Acad. Sci. U. S. A. 109, 20431-20436.

(61) Bellingham, C. M., Woodhouse, K. A., Robson, P., Rothstein, S. J., and Keeley, F. W. (2001) Self-aggregation characteristics of recombinantly expressed human elastin polypeptides. Biochim. Biophys. Acta, Protein Struct. Mol. Enzymol. 1550, 6-19.

(62) Scott, S. R., and Hasty, J. (2016) Quorum Sensing Communication Modules for Microbial Consortia. ACS Synth. Biol. 5, 969-977.

(63) Abe, H., Wakabayashi, R., Yonemura, H., Yamada, S., Goto, M., and Kamiya, N. (2013) Split Spy0128 as a potent scaffold for protein cross-linking and immobilization. Bioconjugate Chem. 24, 242-250.

(64) Woolfson, D. N. (2005) The design of coiled-coil structures and assemblies. Adv. Protein Chem. 70, 79.

(65) Lee, M. E., DeLoache, W. C., Cervantes, B., and Dueber, J. E. (2015) A Highly-characterized Yeast Toolkit for Modular, Multi-part Assembly. ACS Synth. Biol. 4, 975-986.

(66) Cormack, B. P., Valdivia, R. H., and Falkow, S. (1996) FACSoptimized mutants of the green fluorescent protein (GFP). Gene 173, $33-38$.

(67) Li, L., Fierer, J. O., Rapoport, T. a, and Howarth, M. (2014) Structural analysis and optimization of the covalent association between SpyCatcher and a peptide Tag. J. Mol. Biol. 426, 309-17. 